www.conferenceie.ase.ro

\title{
A GENERAL FRAMEWORK BASED ON IOT TECHNOLOGY FOR SMART GOVERNANCE
}

\author{
Dora COARDOS \\ National Institute for Research and Development in Informatics \\ dora.coardos@ici.ro \\ Eugenia TÎRZIU \\ National Institute for Research and Development in Informatics \\ eugenia.tirziu@ici.ro \\ Maria GHEORGHE-MOISII \\ National Institute for Research and Development in Informatics \\ maria.moisii@ici.ro
}

\begin{abstract}
The paper presents research on the concept of intelligent government in the context of the use of IoT technologies and wireless sensor networks. Smart governance targets the future of public services and focuses on using new technologies to streamline decision-making and management processes. The extending of modern ICT capacities and the increasing need for information services systems widespread impose the need to find solutions to the interoperability problems at the technical, informational and organizational level. Our research has focused on interoperability issues and on finding solutions to the challenges process of moving from eGovernment to smart governance. Finally, the paper presents a general framework architecture for smart governance, based on new IoT, fog and Cloud technologies. It is proposed to redesign the ICT infrastructure by virtualizing network resources and data and using advanced data analysis methods to enable better collaboration between government, government institutions, the business environment and citizens.
\end{abstract}

Keywords: cloud computing, fog computing, IoT, smart governance.

JEL classification: $\mathrm{H} 11, \mathrm{H} 33, \mathrm{O} 33$.

DOI: $10.12948 / \mathrm{ie} 2019.06 .03$

\section{Introduction}

For a country to achieve progress according to the time paradigm, it must be borne in mind that the country as a whole must relate to contemporary ideals. Today's technology is one of the most representative aspects of today's society. The intelligent government is the use of technology with the overall goal of upgrading and supporting better planning and decisionmaking in governance by transforming the way public services are delivered and improving democratic processes. Its purpose is to have a very efficient, related to its time, flexible and continuously valorized country through innovation. The smart government is considered "the highest stage in the modernization of public organizations" and contains "reflection, information and processing elements, and is based on the principles of openness, participation and improvement of public sector services" [1].

The Internet of Things (IoT), a concept that has gained increasing importance in recent years, comes in the context of a intelligent government and is one of the key trend governments have to follow in the near future. In order to successfully implement IoT in the context of smart governance, various aspects need to be considered, in particular the development of new business models, the creation of IT infrastructures and decision support systems to streamline 
decision-making and management processes. IoT can be perceived as an open and comprehensive network of intelligent objects that have the ability to organize, share information, data and resources, react and act in front of situations and changes around [2]. The rapid development of ICT enabled the re-examination of the role of new technologies in transition from eGovernment to smart governance, from information society to smart society. The development of a smart government system and its implementation is a complex and longlasting process. This requires interoperability at organizational, informative, technical and pragmatic level. Among the solutions for transforming the information society into a smart society are relevant: redesigning ICT infrastructure by virtualizing network resources and data, using advanced data analysis methods, using IoT technologies. Intelligent technologies allow rapid deployment of innovative IT solutions, making them fully available to all public services, regardless of their location or technical level.

\section{Strategic approaches to smart governance based on IoT}

The policy of developing eGovernment has led to a mosaic of applied technologies. Despite all the progress, there are still some deficiencies in the functioning of eGovernment, such as: the fact that public authorities collect data of interest but do not use them in a functional way; the lack of adequate technical and regulatory conditions limiting the use of these data to a single state authority; the low degree of integration and interoperability in the functioning of governmental organizations affects the efficiency of the exchange of data between different levels of functioning of the system in all its organizational structures.

Establishing effective and transparent communication between governmental organizations G2G is a prerequisite for better communication with citizens - G2C and other business entities - G2B [3]. For this it is necessary: defining a strategy on how to establish the government's interoperability framework and overcoming legal and organizational deficiencies; systematization of administrative procedures and interconnection of different public administration organizations; developing new interfaces to connect existing databases to a single service bus and create new web services. It is also essential to solve technical problems related to: the lack of a unique presentation interface to address the different data structured in databases that can be found in various public administrations locations; the lack of advanced data analysis to obtain accurate information from available data in different formats; improving the quality of services. The rapid development of advanced technologies and methods of data collection, processing and management has led to the expansion of intelligent environments. The constant development of these technologies, from a technical, organizational and other point of view, enables society to transform from an information society into a smart society. The creation of new intelligent electronic services is a very complex task requiring a higher degree of integration and cooperation between computer systems. From a technical point of view, the main challenges for the intelligent government system are:

- Interoperability - requires not only that the systems are connected in the network, but also that the data in each system is interoperable.

- Accessibility - a simple mechanism for approaching data from different locations.

- Availability - both at the main components and at the system level to prevent failure.

- Connectivity - IoT devices require good network connectivity to provide unstructured data and streaming data (eg. rainfall reports, disaster information, patient medical records, etc.).

- Scalability - Applying virtualization technology and creating a cloud environment to respond promptly to new users' requests and to dynamically reallocate resources.

- Security - guarantees for the confidentiality and integrity of all transactions that citizens and users have made within the intelligent government system. 


\section{Interoperability in the field of smart governance}

Interoperability of information guarantees the exchange and automatic interpretation, meaningful and accurate of information. In practice, combining the information collected with those obtained from other databases as well as data analysis is a problem and complicates the realization of joint services. It is therefore necessary to adopt a common method and common structure of information.

For the development of intelligent governments, cooperation and communication between different IT systems is needed. In order for the existing eGovernment architecture to be able to meet the needs of a modern, intelligent society, a higher level of organizational and technical abstraction of the eGovernment system must be imposed, allowing smart governance [3]. Below are five fundamental dimensions of interoperability:

- Organizational Interoperability - refers to the possibility for different entities to collaborate, despite their differences in decision-making;

- Technical interoperability - refers to the technical aspects related to connecting the information system, integrating data and middleware, accessibility and security.;

- Interoperability of services - refers to the identification, preparation and creation of functions that integrate independent services as well as the interconnection of heterogeneous and distributed databases;

- Application Interoperability - aims to integrate applications so they work together;

- Data Interoperability - refers to the interoperability of different data models (relational, hierarchical, and object-based) and different programming languages in order to find and distribute information from heterogeneous sources.

The transition from eGovernment to smart governance is only possible through the use of new generation information technologies to support:

- High level of resource integration to guarantee cooperation and exchange of information between different state bodies.

- Orientation to all elements of society (citizens, enterprises, social and other organizations) and work in their own interest.

- Accurate analysis of data, beneficial to state bodies in the decision-making process.

- The guaranteed security of the information released.

\section{The potential of smart governance}

Digital transformation is essential to modernizing the public sector. Recent technologies create the potential of a wide range of new applications, from information channels and communication channels to new ways of involving citizens in the political process.

Innovative technologies in recent years, such as IoT, Wireless Sensors, Big Data and Artificial Intelligence have become increasingly important and promising. They marked the beginning of a new wave of digitization, not only in the private sector, but also in the public sector. They raise new expectations for public sector organizations, for example, to improve their service quality and cost efficiency by using these technologies and related applications with private sector organizations. Currently, IoT technology is growing at a rapid pace, and the number of connected devices has increased considerably in recent years, creating expectations among governmental organizations about their potential to create value.

Many Smart City initiatives have described the potential of these technologies. Although they are at an early stage of development, these initiatives bring a new service delivery model for public services: the Smart Government. Some Smart City initiatives have made changes in various areas, such as public transport and energy networks, public health monitoring, but all this will require new ways of ensuring timely flow of data between millions of connected IoT devices, chosen for applications that perform critical tasks [4]. 
Even more than previous eGovernment initiatives, smart governments are trying to use sophisticated information technologies to interconnect and integrate information, processes, institutions and physical infrastructure to better serve citizens and communities. Smart governments are pursuing this by connecting physical, digital, public and private environments [5].

To demonstrate the potential of IoT use in public services, an analysis [6] was carried out on the operations of entities such as central government agencies and independent administrative corporations as well as the role of sensor technology in the areas of information gathering, policy implementation and resource management. Within each domain, potential uses with IoT technology have been identified.

Information gathering domain - includes activities such as statistical studies on the easy use of light sensors (such as cameras), smart phones, vehicle sensors, objects, in various environments, even people. Possible uses: facial expression analysis to measure user satisfaction among surveyors at government offices; to analyze the identification of locations where there is a high frequency of vehicles that suddenly brake to improve safety

Implementation policy domain - include activities such as over-the-counter services, border control procedures, taxation and public works. These are areas where progress has already been made in the use of sensor technology. Possible uses: new methods of taxation based on parameters such as: using the vehicle is determined by means of auto sensors, GPS use to obtain a general disaster situation and other emergency management, the use of microwave sensors to identify people who behave suspicious when passing through customs

Resource management domain - includes activities such as staff management, property and building management, and budget management. Possible uses: monitoring the health status of staff engaged in special tasks that require a high level of physical or mental stress; monitoring the movement of staff and; assessing the aging of government buildings.

\section{General Framework Architecture for Smart Governance}

The paper presents general framework architecture for smart governance (see figure 1). The smart governance architecture involves the integration of heterogeneous information systems and the realization of a unified system. This can be done either by upgrading existing systems with new functionalities or by replacing existing infrastructure with a government cloud computing.

Next, an smart governance architecture based on IoT, cloud computing and fog technologies will be presented. The proposed architecture is structured on four main levels: IoT, (for data generation), fog computing, the government cloud computing level (containing the central smart government architecture) and the platform for web applications.

1. Data Collection Level - is the closest layer to the end-user and the physical environment. It is made up of various devices (environmental sensors, smart sensing devices, intelligent devices, etc.) that are generally widely distributed geographically [7]. This layer acquires data from physical objects or events and is transmitted wirelessly or wired to the top layer (fog computing) for processing and storage. IoT devices help public administration by monitoring and managing parking, traffic, lighting, security and environmental control. Sensors for parking, traffic, lighting, environmental control, pits and transport make possible new services involving infrastructure, buildings and public transport.

2. Fog Level - is located close to the edge of the network and is made up of a large number of fog nodes: routers, gateways, switches, access points, base stations, specific fog servers, etc. Data in Fog computing is analyzed, pre-processed and filtered [8]. If anomalies are detected or unusual occurrences are detected in the data received, resources from Fog Computing send alerts to the government cloud and then to IoT devices, thus allowing faster response times. 
The results of anomalous operations are sent to the government cloud computing to combine the results of the various Fog resources [4]. Fog computing improves efficiency and reduces the amount of data that needs to be sent to the government cloud for processing. The purpose of Fog computing is to complement the cloud instead of replacing it.

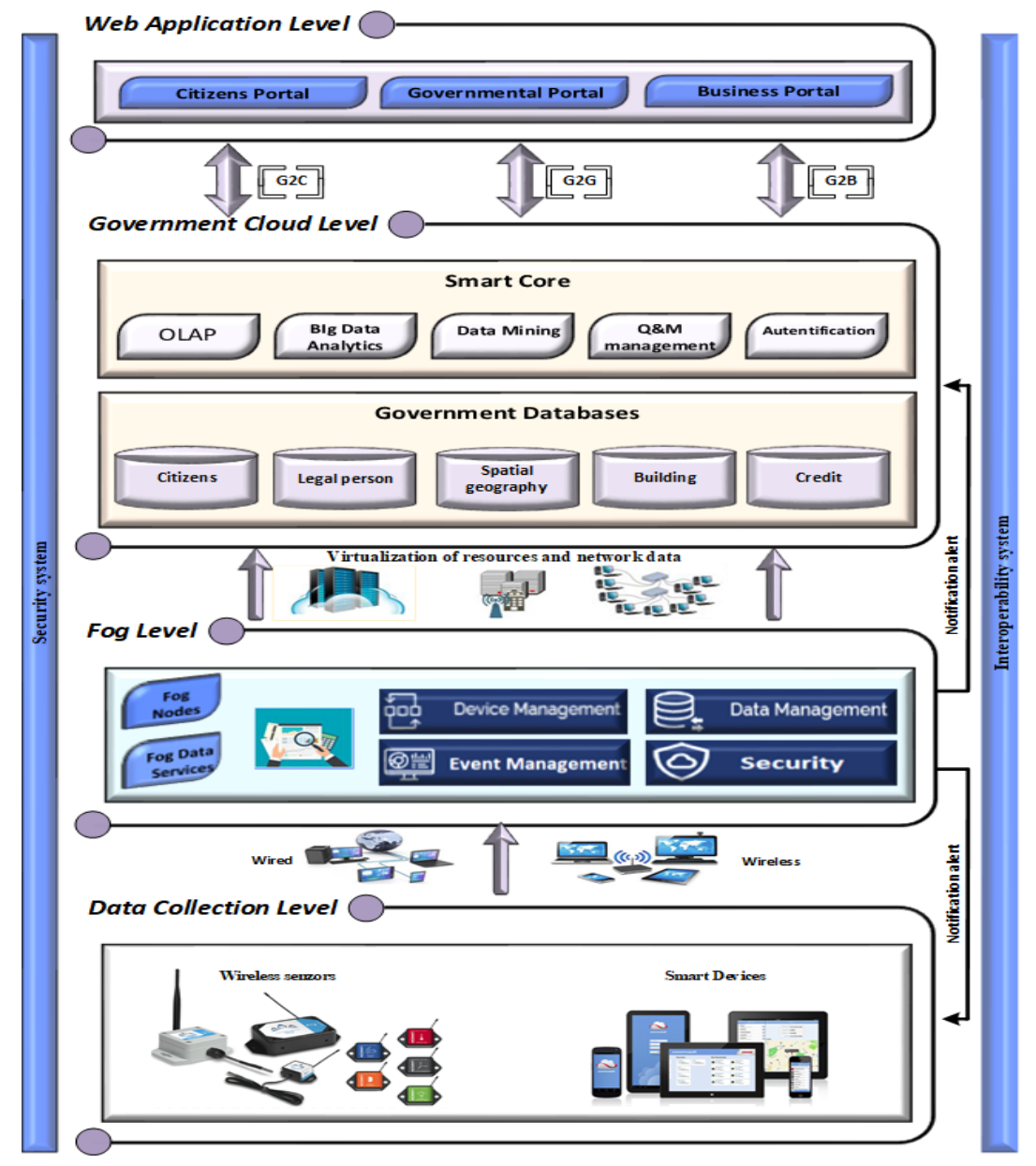

Figure 1. General framework architecture for smart governance

3. Governmental Cloud Level - is made up of several high-performance servers and storage devices. It has powerful computing and storage capabilities, being used for computational analysis and permanent storage of a huge amount of data. However, not all computing and storage tasks are performed in the cloud. To improve the use of cloud resources, the cloud core modules are efficiently managed and programmed through appropriate control strategies [9]. At this level, the central unit of smart governance architecture is met. Here, you can create and deploy services that are a set of interconnected tasks that are consistent with defined procedures and requirements, using the technologies: Big Data, OLAP (Analytical Processing), Big Data Analytics [10].

4. The platform level for web applications and services - is addressed to users through three unique portals: Government, Citizens and Business. Through these portals, the government provides a one-stop service to citizens, the business environment and other government institutions. Analysis and calculations result as well as alert notification are available and can be used by users and government authorities.

The proposed architecture implies both interoperability at the organizational, technical, data and application levels and the use of a security system to ensure the safety, functionality and availability of the global system. 
www.conferenceie.ase.ro

\section{Conclusions}

Developing the concept of intelligent governmental system and its implementation requires interoperability at organizational, informative, technical and pragmatic level. Intelligent technologies allow rapid deployment of innovative IT solutions, making them fully available to all public services, regardless of their location or technical level.

The proposed smart government architecture creates the premises for future service delivery through the correct detection of requirements, the integration of resources belonging to different IT systems, advanced analysis and intelligent responses to users. This achieves the basic objective of smart governance, namely: efficient and transparent public administration, smart public services and significant social benefits for all stakeholders in society.

The smart governance architecture can handle a large amount of data transmitted by mobile IoT devices as well as wireless network sensors. Thus, this large amount of data generated by IoT devices allows for a new collaboration between government, government institutions, the business environment and citizens.

\section{Acknowledgment}

The authors gratefully acknowledge the contribution of Ministry of Communications and Information Society for funding the project Study on Intelligent Behavioral Analysis Systems (at Institutional and User Level) on Online Public Services, 2018-2020.

\section{References}

[1] R. Kennedy, "E-regulation and the rule of law: Smart government, institutional information infrastructures, and fundamental values", Information Polity, 21 (1), pp 77-98, 2016.

[2] G. K. Behara and R. Myadam, "IoT in connected Government helps to deliver better citizen services and provides transparency", GOVIT Journal, 2017.

[3] Z. Bojovic, D. Klipa, E. Secerov and V. Senk, "Smart Government - From Information To Smart Society", Journal of the Institute of Telecommunications Professionals 11, pp. 3439, 2017.

[4] J. Santos, P. Leroux, T. Wauters, B. Volckaert and F. D. Turck, "Anomaly detection for Smart City applications over 5G low power wide area networks", in Proc. IEEE/IFIP Network Operations and Management Symposium, pp. 1-9, 2018.

[5] C. Rochet and J. D. Correa, "Urban Lifecycle Management: A Research Program for Smart Government of Smart Cities", Revista de Gestão e Secretariado, Vol. 7(2), pp. 1-20, 2016.

[6] T. Hiroyasu and M. Tadashi, "Use of IoT by Government Institutions", Hitachi Review Vol. 65, No. 1, 2016.

[7] A. Alexandru, M. Ianculescu and D. Coardoș, "Smart integration of health data, an agent of change for implementing a holistic approach for a personalised healthcare", Proceedings of the 16th International Conference on Informatics in Economy, pg.164-169, 2017.

[8] E. Hanan., "Internet of Things (IoT), mobile cloud, cloudlet, mobile IoT, IoT cloud, fog, mobile edge, and edge emerging computing paradigms: Disambiguation and research directions", Journal of Network and Computer Applications, pp. 104-140, 2019.

[9] R. Mahmud, F. L. Koch and R. Buyya, "Cloud-Fog Interoperability in IoT - enabled Healthcare Solutions", 19th International Conference on Distributed Computing and Networking,Varanasi, India, ACM, New York, NY, USA, January, 2018.

[10] Y. Sun, Y. Xia, H. Song and R. Bie, "Internet of Things and Big Data Analytics for Smart and Connected Communities", IEEE Access, 4, 2016. 